\title{
PARA ALÉM DO NOME QUE TEM: São Paulo, cidade do trabalho'1
}

\author{
Leila Maria da Silva Blass*
}

\begin{abstract}
Este artigo explora as representações identitárias relativas às diferentes cidades brasileiras, como expressão do jogo de rivalidades entre elas. Nesse sentido, põe em questão o discurso em torno da cidade de São Paulo que a considera, basicamente, como cidade do trabalho, a "locomotiva" do Brasil e, portanto, símbolo do desenvolvimento do país. Um dos objetivos principais seria mostrar que a noção de trabalho inventada na modernidade europeia ocidental modela o ideário sobre as cidades, como, por exemplo, o do Rio de Janeiro e de Salvador. Os cartões postais adquiridos, em setembro de 2002, respectivamente no Aeroporto de Congonhas, ao sair de São Paulo para a cidade do Rio de Janeiro, e ao embarcar, no Aeroporto Santos Dumont, para retornar a cidade de São Paulo, são concebidos, na análise aqui proposta, como metáforas visuais, e algumas composições musicais seriam metáforas sonoras. Constituem, assim, a sua principal fonte de dados.
\end{abstract}

Palavras-chave: Cidades. Representações sociais. Estigmas. Trabalho. Emprego.

\section{INTRODUÇÃO}

Em São Paulo, trabalha-se; no Rio de Janeiro, diverte-se; em Salvador (Bahia), festejase o Carnaval e inúmeras festas religiosas; e, na moderna Brasília, capital da república, faz-se política.

Embora essas visões sejam simplificadoras e estigmatizadas de realidades sociais mais complexas, quando prevalecem sobre outras possíveis, elas não só se tornam dominantes, mas também consolidam discursos sobre as cidades. Nessa medida, ganham estatuto de representações identitárias resultantes de um processo de criação e de reatualizações no confronto com as

\footnotetext{
* Pontifícia Universidade Católica de São Paulo, Faculdade de Ciências Sociais, Programa de Estudos Pós-graduados em Ciências Sociais, Departamento de Sociologia, Rua Monte Alegre, 984. Perdizes. Cep: 05014901. São Paulo - São Paulo - Brasil. leilamsb@pucsp.br

${ }^{1}$ A ideia deste texto surgiu no decorrer da palestra "São Paulo de braços fechados? O receptivo em São Paulo", proferida durante I Semana de Turismo que aconteceu na Faculdade de Ciências Sociais da PUC de São Paulo em setembro de 2002

${ }^{2}$ Esse trecho é de autoria de António J. Goncalves e Nuno A. Silva, extraído de uma obra cujo título é "Cidades. Pessoas", Tabacaria (12), publicado em Lisboa pela Casa Fernando Pessoa em outono de 2003.
}

outras, ou seja, no jogo das rivalidades entre cidades. Nesse processo, determinados elementos das paisagens urbanas ganham maior relevância simbólica do que efetivamente possuem, fazendo emergir, assim, estereótipos que lhes são associados.

Importa assinalar, conforme lembra Fortuna e Peixoto (2002, p. 17), que os estereótipos são uma "fonte de pressão para a produção de inferência a partir da informação que veiculam”, de modo bastante amplo. Nessa medida, eles constituem pontos relevantes para análíse, condicionando, para esses autores, processos e discursos representacionais que produzem e reproduzem uma pluralidade de imagens, sejam elas "reais ou imaginárias, instantâneas ou duradoras, de consenso ou de conflito, individuais ou coletivas" (Fortuna e Peixoto, p. 18), que são partilhadas, de modo desigual, entre diferentes grupos sociais na vida cotidiana das cidades.

Ao se enunciar o nome da cidade de São Paulo, por exemplo, surge, de imediato, a imagem da locomotiva, relacionada à concepção de uma "cidade-máquina", ou seja, que se move por si mesma e sempre em movimento. 
Um rodopiar inebriante cujo ritmo agitado e incessante mostraria uma cidade que não para, contrapondo-se ao vadiar e ao festar.

A cidade do Rio de Janeiro, cenário, por excelência, dos festejos carnavalescos, se complementa com as paisagens deslumbrantes da natureza, com praias encantadoras e repletas de mulheres faceiras e de contornos de corpo invejáveis. No imaginário social, é uma cidade maravilhosa, que convida ao vadiar, ao descanso, às atividades de turismo contrapostas às extenuantes práticas de trabalho propriamente ditas. Desse modo, encontra-se de "braços abertos" para receber estrangeiros e turistas, como simboliza a escultura do Cristo Redendor, no alto do Corcovado.

Salvador, na Bahia, é cidade mestiça, colorida e das festas. O festar marcaria sua vida cotidiana onde o esforço requerido pelo trabalho assalariado se desenvolve, de modo intermitente, e parece fora de lugar. Uma cidade pontuada por atividades consideradas de entretenimento e voltadas aos de fora de suas fronteiras, ou seja, ao lazer dos trabalhadores assalariados vindos, principalmente, da cidade de São Paulo, bem como de outros países ou regiões brasileiras.

Brasília, a capital federal, é um dos ícones da cidade planejada, também conhecida 놀 como uma "ilha de modernidade", incrustada : no sertão, ou melhor, no pantanal, distante do vasto litoral brasileiro. Expressão das conquistas históricas do oeste, tornar-se-ia, a partir dos anos 60 do século passado, um palco privilegiado das inúmeras decisões políticas e negociações que se desenrolam no efetivo exercício ז dos poderes de Estado. Assim, concentra uma a significativa quantidade de órgãos, autarquias $\stackrel{\infty}{\sim}$ e instituições vinculadas ao governo federal,

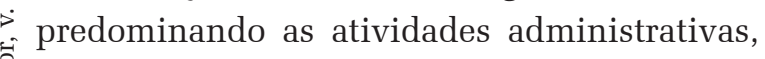
condensadas no chamado serviço público.

As imagens dizem respeito às paisagens urbanas, mas respondem ao jogo das rivalidades entre as cidades brasileiras. Como tais, acabariam por informar os estudos e as várias propostas de intervenção urbana na imple- mentação de projetos governamentais e de Estado. Para tanto, são ressaltados certos traços e não outros, pondo a descoberto algumas características a fim de mostrar a vocação local e (ou) regional de cada uma delas.

Os discursos sobre as cidades expressam, portanto, um processo de construção imagética cujas ideias se difudem historicamente, estigmatizando-as, muitas vezes. Marcas e etiquetas, que parecem perdidas na memória, emergem, vez por outra, em falas que balizam lugares e comportamentos. Indicam, portanto, o grau de aderência de moradores e habitantes, inclusive, aos pressupostos do processo de acumulação capitalista, como se observa na cidade de São Paulo, onde se expressam, de modo mais evidente, aspectos relativos ao progresso e desenvolvimento da sociedade brasileira. Esses aspectos podem compor um ideário de trabalho que associaria a denominação "cidade do trabalho" à cidade de São Paulo. Nesse sentido, caberia indagar: que ideia de trabalho que informa essa representação social? Aquela que se confunde com emprego fabril e febril? Ou seja, as imagens difundidas sobre o viver na cidade nomeiam São Paulo antes mesmo que seja pronunciado seu nome, ativando, por conseguinte, um conjunto de sentimentos e de expectativas que permitem logo reconhecer de que cidade se trata.

Embora os guias turísticos contenham, como sugere Barreira (2009, p. 221), narrativas das cidades, ao apontarem, comenta essa autora, "[...] disputas simbólicas entre localidade, classificações e valorização de “tradições”, eles não foram consultados para elaboração deste artigo. As representações das cidades serão aqui exploradas através das imagens divulgadas nos cartões postais da cidade de São Paulo, em contraposição às do Rio de Janeiro e a partir de algumas composições musicais.

Os cartões postais constituem, como metáforas visuais, a principal fonte de dados deste artigo e foram adquiridos em setembro de 2002, no Aeroporto de Congonhas, ao sair de São Paulo para a cidade do Rio de Janeiro, 
e ao embarcar no Aeroporto Santos Dumont, para retornar à cidade de São Paulo.

Algumas melodias, como metáforas sonoras que tematizam, em seus versos, fragmentos cotidianos vivenciados na cidade de São Paulo serão recuperadas, como acontece com as canções bastante conhecidas "Sampa" de Caetano Veloso e "Trem das Onze" de Adoniran Barbosa.

Apesar de compor, segundo Canevacci (1993), uma polifonia urbana, elas assinalam, assim como os cartões postais, aspectos parciais de uma cidade. O mesmo se observa quando se trata de uma determinada sociedade ou parte dela, lembra Becker (2009). Importa, nesse sentido, assinalar que os cartões postais autoapresentam e autorrepresentam as cidades, podendo suscitar uma reflexão sobre elas. Do mesmo modo, palavras e expressões evocadas nos versos de algumas composições musicais chamam a atenção, sublinhando traços marcantes de uma cidade. Nesse sentido, informam sobre as cidades de modo semelhante ao que acontece com outras fontes de dados. Como sugere Becker (2009, p. 31), “[...] representação da realidade social - um filme documentário, um estudo demográfico, um romance realista [...] são sempre parciais, ao relatarem [...] apenas aquilo de que os usuários precisam para realizar o que quer que queiram fazer."

Os fotógrafos narram algo através das imagens que criam e são divulgadas em reportagens, nas campanhas publicitárias e ainda nas ilustrações. Para tanto, selecionam e definem certos detalhes que implicam desprezar outros e transferir a tarefa de interpretação para os usuários ou consumidores de suas fotos. Como acentua Becker (2009, p. 46), “[...] embora as fotos sejam compostas com cuidado, de modo que os detalhes não sejam apenas um ruído aleatório, os observadores podem interpretá-los de muitas maneiras, dependendo dos detalhes que enfatizam e de como os compreendem."

Nos cartões postais, são ressaltados certos aspectos que correespondem, por vezes, às singularidades da história de cada cidade. Na mesma medida, ficam ocultados o protagonismo de atores e atrizes no cenário urbano, embora, como sugere a epígrafe deste texto, os traçados urbanos sejam construídos e reconstruídos por seus moradores e habitantes cujas histórias reverberam nos edifícios e ressoam nas ruas, praças e avenidas por onde passam. As pessoas se encontram, invarialvemente, ausentes dos cartões postais. No caso da cidade de São Paulo, essa situação salta aos olhos. As imagens mostram, de modo recorrente, edifícios cada vez mais altos, marcando a verticalização das moradias; os inúmeros viadutos e pontes estaiadas que se espalharam pela cidade, principalmente, na primeira década do século XXI, assim como ruas e avenidas lotadas de veículos, dificultando a mobilidade urbana.

Em contraposição, nos cartões postais da cidade do Rio de Janeiro, predomina o cenário da natureza tropical que combina mar, praia, sol, montanhas e outras belezas naturais. No entanto, as redondezas do Paço Imperial e do Palácio do Catete, centro político do Império e da República no Brasil, são tão pouco tematizadas que se torna necessário conhecer as informações contidas nas legendas a fim de saber o que retratam as imagens e em que cidade se localizam.

No caso da cidade de São Paulo, fica tão evidente a "selva de pedra" (ou de concreto?) que requer um esforço de imaginação para reconhecer outros aspectos que compõem sua paisagem urbana. Em outras palavras, torna-se muito difícil, para muitos de seus moradores, aceitar o fato de que nem sempre a cidade de São Paulo esteve marcada pela multiplicidade de atividades artístico-culturais e apresentou um significativo patrimônio histórico.

Relembra, nesse sentido, Lemos (1979, p. 11):

São Paulo sempre foi muito pobre, inclusive nos tempos iniciais do café e até mesmo por ocasião da estrada de ferro dos ingleses. Sempre dependeu muito da roça, dos pequenos sítios de agricultura de subsistência que eram acessíveis por um emaranha- 
do de péssimos caminhos rurais e pequenas estradas que vieram a ter, no futuro, papel importante na expansão da cidade.

São raros os cartões postais que focalizam, por exemplo, as diversas esculturas espalhadas pela cidade, exceto a escultura do Brecheret, localizada no Parque Ibirapuera, em frente ao prédio da Assembleia Legislativa de São Paulo, retratando o "Espírito Bandeirante", uma das heranças históricas do período das "entradas e bandeiras" que leva à conquista do Oeste brasileiro e, por conseguinte, a ampliação das fronteiras geográficas do Brasil. Alguns intrepretam essa imagem à luz de experiências mais recentes, isto é, "o empurra- empurra" nos transportes urbanos ou nas vias públicas paulistanas sempre repletas de carros e de gente.

Locais importantes do processo histórico de formação da sociedade brasileira ou ainda a pluralidade do patrimônio arquitetônico presente na cidade de São Paulo são pouco veiculados. A exceção seria o Pátio do Colégio, que condensa o mito fundador dessa cidade, protagonizado pelo Padre José de Anchieta, ou resultante dos contatos dos jesuítas portugueses com os povos indígenas habitantes tradicionais das terras brasileiras. Do mesmo modo, pouco se menciona o "centro velho da cidade", onde se decidiam grandes negócios relaciona늠 dos com a dinâmica econômica do Segundo : Império e das primeriras décadas do período republicano, marcado pela produção e comercialização do café.

Nesse sentido, é importante notar que a Avenida Paulista seria a própria imagem do espiríto vigente na cidade de São Paulo, do ponto de vista dos paulistanos, conforme os resultados de um plebiscito popular realizado entre 1992 e 1993. A escolha da "moderna" Avenida Paulista como "a cara de São Paulo" indica, sem dúvida, a reafirmação do ideário do trabalho, progresso e desenvolvimento da capital paulista visto que ela constitui o locus privilegiado do capital financeiro, ao concentrar, em seu entorno, as principais sedes administrativas de bancos, incluindo o Banco Central do Brasil, e de várias empresas transnacionais. Assim, os altos e modernos edifícios ocupam os terrenos dos "casarões da aristocracia cafeeira”, mostrando o encerramento de uma época: os chamados "anos dourados" da economia cafeeira e o seu papel na geração do capital bancário e industrial no país.

A análise deve apontar, contudo, além dos atributos que lhe são auferidos. Deve explorar os não ditos, os silêncios dos registros históricos, por exemplo, das práticas de trabalho escravo ou da inserção do trabalhador nacional - negros e índios - nas atividades artesanais e urbanas que criam as condições sociais para o desencadear do processo de industrialização em São Paulo. Por isso, pretendo, neste artigo, relacionar a noção de trabalho, inventada na modernidade europeia ocidental, com as representações sociais sobre as cidades o que, no caso da cidade de São Paulo, se fundamenta no ideário do trabalho assalariado, como fonte de geração de capital e, portanto, do processo de desenvolvimento capitalista brasileiro. A ideia moderna de trabalho informaria, dessa perspectiva, as marcas atribuídas às diferentes regiões e cidades e, principalmente, a visão de mundo e as práticas sociais de seus moradores e habitantes. Portanto, a difusão das imagens sociais relativas à cidade de São Paulo referese a ela propriamente dita e, ao mesmo tempo, se torna o parâmetro a partir do qual todas as demais cidades são avaliadas quanto ao papel econômico e político desempenhado na sociedade brasileira.

\section{TRABALHO COMO LINGUAGEM}

Quando se trata da emergência, no Brasil, do trabalhador assalariado, a literatura sociológica e histórica privilegia o estado de São Paulo, que concentra, nas suas várias regiões, o principal setor agroexportador da economia brasileira no final do século XIX e início do século XX: a lavoura cafeeira. Esses estudos enfatizam, de um modo geral, a intervenção di- 
reta do Estado através da promoção de uma política imigratória cujo objetivo principal seria suprir, rapidamente, as demandas de mão de obra desse setor. Se essa medida atendia a interesses imediatos dos seus representantes, contribuiria, mais tarde, para o desenvolvimento industrial nesse estado, quando se consolida a presença do trabalhador nacional "livre" e a generalização de várias formas de assalariamento tanto no campo quanto nas cidades. E, justamente, este aspecto predefine e classifica as diferentes formas de vida societária, tomando-se a emergência da fábrica moderna, na sua universalidade abstrata, e o emprego fabril como um dos critérios fundamentais para se reconhecer a chamada "sociedade do trabalho", à medida que a expansão do emprego nas grandes empresas, particularmente, fabris, constitui um dos pressupostos do processo de acumulação do capital para a realização do ciclo - produção, distribuição e consumo.

Os fazeres artísticos e (ou) as atividades dos artífices pouco influem nessa dinâmica. Ao contrário, dependem, até certo ponto, desse processo, porque não atendem aos requisitos fundamentais do estatuto de trabalho assalariado como fonte de geração de valor. Dessa perspectiva, são designadas, muitas vezes, como lazer e enquadradas nas práticas de tempo "livre", que fariam parte do chamado mundo do não trabalho. Nessa medida, emprego fabril se confundiria, no imaginário social, com trabalho, embora seja uma das formas históricas que o trabalho assume nas sociedades modernas.

O tempo social responde às regulamentações da jornada de trabalho vigente em uma determinada sociedade, separando-se, de um lado, tempo de trabalho e, de outro, tempo livre. Assim, o trabalho se contrapõe a atividades de lazer, confundidas com ócio, e parece desvinculado do sagrado, das cerimônias religiosas e das manifestações do sobrenatural, ou seja, do sistema de relações sociais. $\mathrm{O}$ ato de trabalhar, como ato criativo, perde sua magia e estaria distante de qualquer fonte de prazer.

Os olhares das Ciências Sociais e da
Economia Política, fundados no ideário iluminista, voltam-se, completamente, para as oscilações do emprego, na sua dimensão de labor, ignorando as possibilidades do trabalho como obra. Essa visão permanece, apesar da crescente expansão dos índices de emprego não fabril, das mudanças na jornada de trabalho e no tempo regularizado do não trabalho, nas sociedades contemporâneas.

Convém lembrar, nessa direção, que o lazer ou diversão de uns supõe o trabalho e (ou) emprego de outros. Se, de um lado, estão os consumidores das atividades de lazer, de outro, se encontram os seus fazedores, como, por exemplo, da produção literária, cinematográfica, televisa; dos espetáculos de dança e de teatro; dos concertos musicais, das exposições de artes plásticas, das competições esportivas, dos festejos, das celebrações, etc. Todas essas atividades são resultantes de uma multiplicidade de processos de trabalho que perseguem diferentes formas de organização.

Embora a heterogeneidade dos processos produtivos e das práticas de trabalho apresentem contornos mais nítidos no tempo presente, no caso da formação social brasileira, a diversidade constitui um dos seus aspectos fundantes. Ou seja, é resultado do entrecruzamento de heranças culturais indígenas, das experiências históricas com a escravidão negra e da imigração de europeus e orientais para o estado de São Paulo e, particularmente, para a capital paulista.

Os estudos sobre a questão do trabalho na sociedade brasileira desconsideram esses aspectos e tomam a emergência da fábrica moderna e do emprego fabril como modelos no estudo do processo de formação do trabalhador assalariado brasileiro, reafirmando a dicotomia, portanto, mundo do trabalho e do não trabalho. Em oposição ao mundo do trabalho, que condensa um conjunto de sentimentos negativos relativos à obrigação, ao castigo, ao sofrimento, isto é, à cruz que se deve carregar, as atividades de não trabalho podem ser vistas como positivas na medida em que podem 
garantir a recuperação da fadiga causada pela venda da força de trabalho a outrem e possibilitar momentos de descanso, repouso e ócio.

Essa perspectiva de análise se funda no trabalho assalariado e, nesse sentido, persegue os pressupostos epistemológicos da Economia Política. O desafio residiria na exploração de outros aspectos como, por exemplo, as interrelações da festa e de outras práticas culturais com trabalho. Conforme assinala Fortuna (1995, p. 6), não se pode esquecer que as chamadas atividades de lazer, bem como um conjunto de outras atividades sociais, “[...] não são a antítese da vida cotidiana, mas antes a sua continuação, mesmo se dramatizada [...]" e apresentada através das diferentes soluções estéticas.

Essa questão salta aos olhos, ao se acompanhar, como mostrei em outro estudo, a produção dos desfiles carnavalescos em duas importantes escolas de samba da cidade de São Paulo (Blass, 2007). Essa produção abrange desde a confecção das alegorias, adereços e fantasias para milhares de brincantes, o que acontece durante vários meses, no barracão das escolas de samba e nas oficinas agregadas, até a elaboração dos sambas-enredo e os ensaios da bateria, dos casais de porta-bandeira e mestre-sala. Nesse processo, as atividades de trabalho e de emprego aparecem fundidas e 농 misturadas no chamado mundo do não traba. lho, instalando uma reflexão teórica a respeito da noção moderna de trabalho e a dicotomia efetuada pelo pensamento sociológico ocidental moderno, que separa, classifica e opõe trabalho e lazer ou não trabalho.

As mesmas questões surgiram no estudo (Blass, 2004) em torno dos festejos de Dois de Fevereiro, realizados em homenagem a Iemanjá, que acontecem todos os anos na cidade de Salvador (Bahia). Essa manifestação festiva, embora seja religiosa, como tantas outras que ocorrem no Brasil, extrapola o sagrado. Está em jogo, contudo, uma concepção do sagrado que invade toda a vida, integrando o conjunto das atividades sociais. Essa festa celebra o trabalho dos pescadores e (co)memora a produção pesqueira passada e futura, a fim de garantir a oferta e abundância da pesca, como alimento para o corpo de homens e mulheres.

Um aspecto profano, talvez um dos mais sagrados, motiva e justifica a própria festa de Dois de Fevereiro em Salvador, pois traz à tona algumas questões referentes à fertilidade e à abundância da natureza na oferta de alimentos, que são fundamentais para preservação da própria vida. Dessa perspectiva, os festejos para Iemanjá viram do avesso a ideia de trabalho, fundada na fragmentação das práticas sociais e no desencantamento do mundo.

O trabalho possui, portanto, uma linguagem que resulta de tradições culturais herdadas e de várias experiências históricas. Nessa medida, a desconstrução teórica da noção moderna de trabalho coloca-se como imperativo, inclusive, para se desvendar múltiplos significados das representações sociais associadas às cidades. Desse ponto de vista, as fotografias, os cartões postais, guias e pacotes turísticos estabelecem expectativas, realimentando o imaginário social acerca das cidades. Desse modo, escondem mais do que revelam os diversos modos de viver uma cidade.

\section{CIDADES E SUAS CARTOGRAFIAS}

Os moradores da cidade de São Paulo, do mesmo modo que acontece em outras cidades, elaboram cartografias próprias com traçados subjetivos e pessoais. Esses traçados expressam espaços de sociabilidade e de convivência, estabelecendo relações afetivas produzidas e reproduzidas no cotidiano vivido de uma cidade. São essas cartografias reveladoras das inúmeras "cidades" submersas, ou até invisíveis, que configuram um cenário urbano plural, diverso e múltiplo como acontece com a cidade de São Paulo, apesar da sua extensão geográfica e concentração populacional.

Cada bairro paulistano parece constituir-se em uma cidade, pois neles seria possível encontrar equipamentos de uso coletivo 
sem que seus moradores precisem se deslocar ao centro da cidade para resolver questões da vida cotidiana. Essa situação mostra aspectos da sua descentralização, fazendo emergir "vários centros". Por isso, é frequente se encontrar moradores de bairros mais distantes da Praça da Sé, marco zero da cidade, que desconhecem a sua localização e outras referências importantes da vida urbana paulistana porque nunca precisaram sair dos seus bairros.

As cartografias resultantes de tradições culturais e experiências históricas herdadas compreendem também as diferentes etnias a que pertencem os habitantes da cidade de São Paulo. Alguns bairros da capital paulista transformaram-se, ao abrigar os estrangeiros recém-chegados ou já residentes há décadas, nessa cidade. O padrão arquitetônico das residências ou dos condomínios, dos restaurantes e das casas de espetáculos, instalados, por exemplo, no bairro de Itaim-Bibi, bem como na Vila Nova Conceição, buscam atender às demandas dos chamados "trabalhadores globais”, cuja presença crescente em São Paulo expressaria a sua inserção na dinâmica do capitalismo mundial. Observações semelhantes são válidas quando se trata do bairro do Pari, cada vez mais ocupado por sul-americanos, principalmente bolivianos, e, o do Bom Retiro pelos coreanos.

As contradições entre opulência, riqueza e pobreza, entre desenvolvimento e desigualdades sociais são evidentes na paisagem urbana de São Paulo. No entanto, são as manifestações artístico-culturais que trazem à tona as ambiguidades e paradoxos de um imaginário homogeneizador, pautado na representação de uma São Paulo como "cidade do trabalho".

Importa ressaltar que muitas dessas manifestações surgem nas margens da cidade, como, por exemplo, as agremiações carnavalescas, e, mais recentemente, as bandas de rap, reggae ou funk. No caso das escolas de samba paulistanas, o bairro ou a região onde elas surgiram são mencionados no refrão, ou mesmo na primeira estrofe dos seus hinos oficiais, de- marcando, assim, o lugar de cada uma na capital paulista.

$\mathrm{Na}$ análise que realizei sobre a quarta edição da Virada Cultural (Blass, 2008) que aconteceu na cidade de São Paulo entre os dias 26 e 27 de abril de 2008, tentei explorar as relações entre a distribuição espacial dos palcos temáticos e o processo histórico de formação multicultural da cidade de São Paulo. Embora seja um evento efêmero e ocasional, voltado para as atividades de entretenimento ou de lazer, tanto a programação quanto essa distribuição respondem ao modo de viver a cidade, à visão de mundo de grande parte dos seus moradores e ao sistema de relações sociais (e de poder) em que estão inseridos. Tanto é assim que os palcos, quase todos, estavam localizados no centro da cidade, entre a Praça da República e o Viaduto Santa Efigênia - o chamado centro "novo" da cidade. O palco D. Pedro seria a única exceção e se destinava, justamente, aos adeptos e protagonistas do movimento hip hop.

Chama a atenção, nesse sentido, esse deslocamento visto que o palco se localizava num local distante e isolado dos demais; bastante deteriorado e completamente entrecortado por vias expressas que interligam as regióes leste e sul da cidade. Os principais protagonistas do movimento hip hop vivem em bairros dessas regiões, sendo considerados os redutos importantes dessa expressão cultural na cidade de São Paulo. Nesse sentido, desnuda-se a segregação urbana na distribuição das atividades artísticas, ao se mostrar a quem se destinam esses palcos. Os integrantes e adeptos do movimento hip hop são reconhecidos na sua diferença, mas, sem deixar de enfatizar sua rebeldia e revolta, são, frequentemente, relacionados aos atos de violência na cidade e aos indicadores crescentes de criminalidade. Assim, as imagens socialmente construídas em torno de jovens moradores nos bairros limítrofes da cidade de São Paulo envolvem também suas manifestações culturais, o que acabaria se tornando uma justificativa para a escolha do Par- 
que D. Pedro como o local mais adequado para sua apresentação musical na Virada Cultural de 2008.

A alocação dos palcos reproduz, portanto, as fronteiras simbólicas que compõem a dinâmica urbana de São Paulo e suas formas segmentadas de sociabilidade, além de revelar as contradições do processo de desenvolvimento capitalista, pontuado por desigualdades de oportunidades, de acesso aos bens culturais e pelos ditames da injustiça social. Mais uma vez, constata-se que o processo de desenvolvimento coexiste com as mais variadas formas de pobreza, que se traduzem em inúmeras muralhas quase imperceptíveis na vida cotidiana paulistana. São muralhas que separam e segregam quem está dentro e quem está fora.

Os participantes das agremiações carnavalescas da cidade de São Paulo e (ou) das rodas de samba também foram contemplados nessa Virada Cultural com um palco temático denominado "Boteco de Bambas", localizado próximo ao viaduto Santa Efigênia e ao Vale do Anhangabaú. Sem dúvida, um lugar simbólico para os sambistas e para os festejos de Carnaval na capital paulista, sendo, inclusive, cantado em versos por Adoniran Barbosa. ${ }^{3}$ A localização desse palco temático também é afastada, como o destinado aos representantes $\stackrel{2}{5}$ do movimento hip hop, das principais atrações : artísticas programadas para acontecer na Vira-

Desse modo, rappers e sambistas estão mais expostos, através de suas manifestações artístico-culturais, ao policiamento e ao exercício das várias formas de controle social soi bre o que dizem e fazem, incluindo os gestos e $\dot{A}$ movimentos corporais do seu público ouvinte.

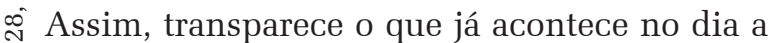
$\therefore$ dia da cidade de São Paulo, porém de modo silencioso e sub-reptício nas chamadas práticas sociais de entretenimento ou de lazer.
Uma das singularidades da vida cotidiana, nessa cidade, seria, como mencionei anteriormente, a mistura, a mestiçagem e a sobreposição de estilos de vida. E a programação da Virada Cultural, como circuito cultural institucionalizado, busca contemplar, justamente, essa dimensão. A presença da cultura foi sempre, lembra Ferreira (2009, p. 319),

[...] um elemento fundamental do funcionamento dos circuitos culturais. Foi sempre, também um ingrediente essencial da modelação dos ambientes urbanos, da forma como neles convivem grupos sociais e modos de expressão diversos e de maneira como as cidades se identificam e distinguem umas das outras.

No jogo de rivalidades entre as cidades, ganham importância crescente as atividades artístico-culturais no sentido de possibilitar a descoberta dos fundamentos de uma determinada ordenação do espaço urbano. Essas atividades acabariam promovendo, para Ferreira (2009, p. 319), “[...] transformações sensíveis nos modos de estruturação e de representação da vida urbana e do espaço público das cidades".

Embora as ações individuais e coletivas de moradores, urbanistas, arquitetos e outros agentes, como atores e protagonistas, possam contribuir para alterar algumas imagens sobre as cidades, mostrando, como sugere Fortuna (2002, p. 59), “[...] para além daquilo que são, no seu plano tangível e material, realidades socialmente apropriáveis e imaginadas[...]", podem facilitar a reprodução de estereótipos. Desse modo, as cidades podem suscitar, continua esse autor, “[...] imagens contraditórias ou conflituais, assumindo, nessa medida, uma identidade difusa e mutável."

No caso da cidade de São Paulo, esse processo ocorre tendo como referência a paisagem urbana, ao lado das comemorações festivas e das expressões musicais como, por exemplo, o samba que se "faz" na cidade do Rio de Janeiro. Esse aspecto se torna evidente quando se trata das representações de São Paulo como "túmulo da samba" e "cidade do trabalho". Essas imagens sociais dão suporte às disputas 
simbólicas entre aquelas cidades. É curioso quando se considera as inúmeras composições musicais que exploram essas temáticas a fim de chamar a atenção para as festas que acontecem em São Paulo no decorrer do ano, no contexto do processo de formação multicultural de seus moradores.

O GRCES "Acadêmicos do Tucuruvi", uma agremiação carnavalesca paulistana, dentre outras, apresenta, por exemplo, no carnaval de 2001 o enredo entitulado "São Paulo dá samba, olha aí nosso carnaval”. O samba de enredo proclama em seus versos:

Se enganou, olha aí, não sou

um túmulo, eu sou feliz

Ganhei um palco pra provar minha raiz[... $]^{4}$

Geraldo Filme, um importante compositor paulista, tendo participado e organizado várias agremiações carnavalescas na cidade de São Paulo, declara, em um dos seus sambas mais famosos, chamado "Tradição", também conhecido como "vai no Bexiga pra ver":

Quem nunca viu o samba amanhecer

Vai no Bexiga pra ver

Vai no Bexiga pra ver

O samba não levanta mais poeira

Asfalto hoje cobriu o nosso chão

Lembrança tenho da Saracura

Saudade tenho do nosso cordão

Bexiga hoje é só aranha-céu

E não se vê mais a luz da lua

Mas o "vai vai" está firme no pedaço

É tradição e o samba continua

$[\ldots]^{5}$

Os sambistas, como moradores da cidade de São Paulo, tentam desconstruir um certo imaginário sobre essa cidade. Ao fazê-lo, contudo, acabariam reforçando aspectos presentes no imaginário social acerca das demais. Um exemplo ilustrativo, nesse sentido, seria a composição "Não é só garoa", de Maurilio de Oliveira e Chapinha, que dizem em seus versos:

${ }^{4}$ Ver: CD "Sambas de enredo das escolas de São Paulo. Carnaval 2001".

${ }^{5}$ Ver: CD “Geraldo Filme: memória Eldorado”.

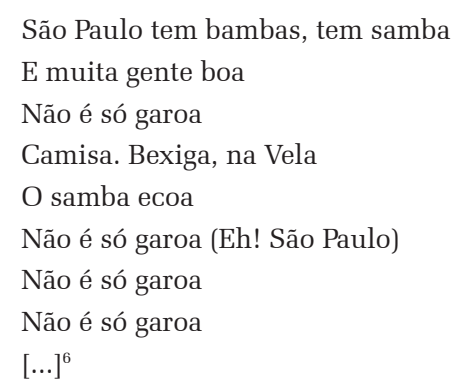

O modo de os moradores identificarem e distinguirem as cidades entre si remete, no caso brasileiro, às imagens social e historicamente difundidas sobre outras cidades avaliadas como ícones da modernidade ocidental, como, por exemplo, Nova Yorque (EUA). Assim, a heterogeneidade e a pluralidade étnica dos habitantes da cidade de São Paulo, acrescidas da proliferação de avenidas e edifícios, inspiram a composição musical São Paulo, São Paulo, do grupo musical "Premeditando o Breque”, divulgada no seu LP "Quase Lindo", lançado em 1983. Essa canção obteve o $2^{\circ}$ lugar, após Trem das Onze de Adoniran Barbosa, considerada uma das músicas-símbolo da capital paulista na votação popular realizada vinte anos depois, ou seja, no ano de 2003.

Com humor, essa canção descreve a heterogeneidade marcante dos moradores paulistanos. Assim, "a japonesa loura” encontra uma "nordestina moura”, e ambas convivem com "gatinhas punks", mostrando o "jeito yankee de São Paulo". Para reforçar ainda mais as ambiguidades da vida cotidiana nessa cidade, essa canção declara, nos últimos versos:

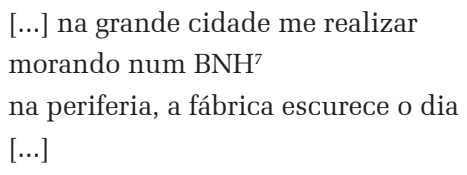

No show "Mundo São Paulo", apresentado em agosto de 1996, no TUCA (São Paulo), José Miguel Wisnik segue nessa trilha com a

${ }^{6}$ Ver: CD “Sentimento Popular”, Quinteto em Branco e Preto. São Paulo, jan 2003.

${ }^{7}$ Banco Nacional de Habitação, criado em 1964, com sede em Brasília, com o objetivo financiar e produzir empreendimentos imobiliários, particularmente conjuntos habitacionais, com base na gestão do FGTS. 
composição "Inverno (Anhangabaú da felicidade)", onde trata dos moradores de rua nas noites frias da cidade de São Paulo. E descreve nos seus versos:

[...] a minha casa é uma caixa de papelão ao relento brasa dormindo contra o vento $[\ldots]$

Além disso, chama a atenção para a contradição entre desenvolvimento, progresso e pobreza, uma das características marcantes das sociedades capitalistas, bastante explorada também por Geraldo Filme em seus sambas. Wisnk e Neves pontuam ainda outro aspecto que se revela na disputa tácita entre paulistanos e cariocas. Esses compositores, na canção “São Paulo Rio”, narram uma situação frequente na vida cotidiana da cidade de São Paulo, em épocas de chuva. Com ironia, cantam os versos:

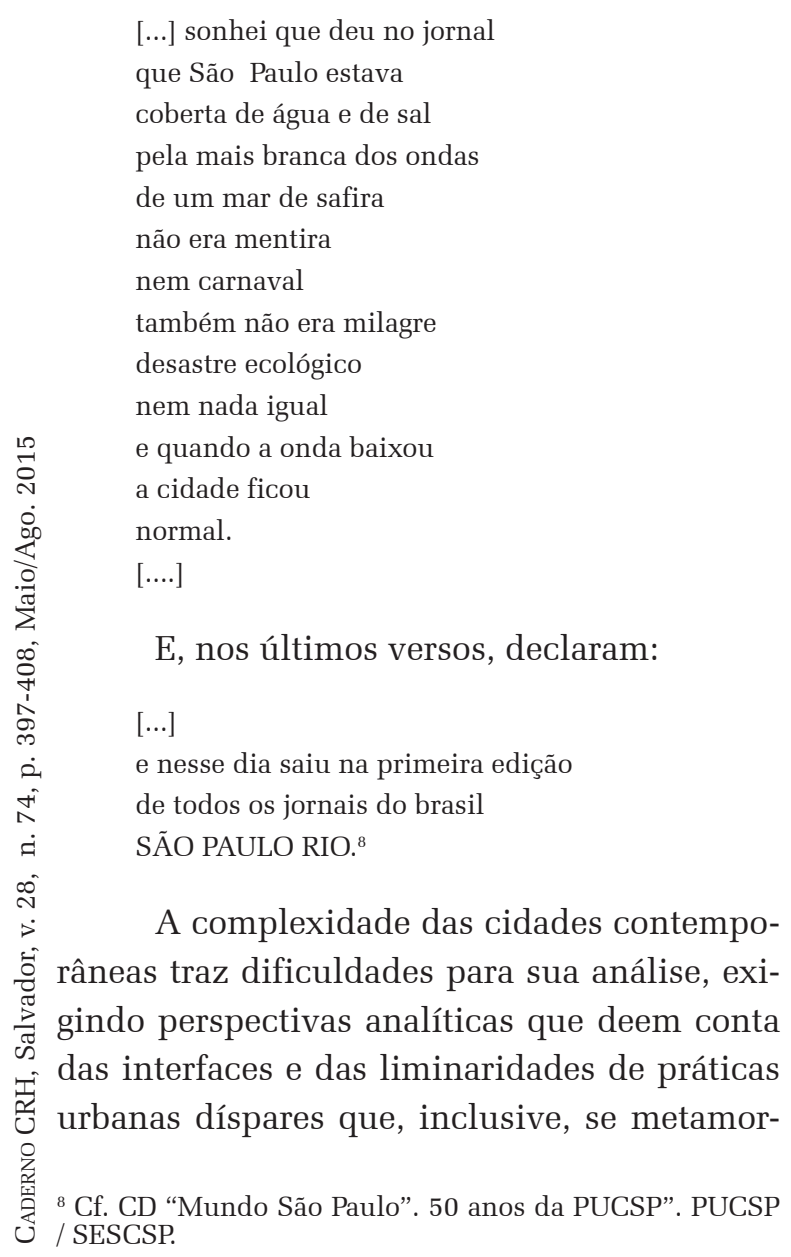

foseiam. No entanto, o ideário socialmente construído em torno das cidades pouco se renova, indicando as disputas simbólicas entre elas, bem como entre regiões.

É forçoso admitir, nesse sentido, que os documentos escritos constituem a fonte de dados predominante nas ciências sociais, apesar do reconhecimento, em décadas recentes, escreve Fortuna (1999, p. 104), “[...] da importância do olhar e da cultura visual da conformação e nos modos de representação da sociedade [...]", compondo imagens, insinuações preciosas do processo de formação das pertenças sociais.

\section{CONSIDERAÇÕES FINAIS}

As cidades respiram a história de seu país, fornecendo sentido e lugar para além do espaço meramente local. Afirmam, assim, sua pertença nacional, mas seus moradores rivalizam entre si quando se trata do papel desempenhado por suas cidades na história nacional.

O local e o nacional têm um peso na formação da autoimagem dos moradores em uma determinada cidade. $\mathrm{O}$ patrimônio relativo à paisagem natural e ao histórico condensam as representações identitárias que atuam, inclusive, no processo de elaboração e difusão de um imaginário social atrelado às cidades como, por exemplo, a de "braços fechados" em contraposição a outras consideradas de "braços abertos".

Dessa perspectiva, a cidade de São Paulo não é aquilo que parece ser. Traz algo escondido na sua topografia de planalto, que convida à sua descoberta.

As representações sociais dominantes e consolidadas em torno das cidades não expressam suas singularidades, quando se consideram os diversos modos de viver uma cidade, ou seja, do ponto de vista dos atores e atrizes sociais que fazem uma cidade no seu cotidiano.

Os símbolos de identidade local nem sempre se encontram impressos nas constru- 
ções arquitetônicas e (ou) nos monumentos. Em algumas cidades, elementos importantes de reconhecimento local, regional ou mesmo nacional estão no conjunto de monumentos, nas manifestações culturais e no projeto urbanístico e arquitetônico. Em outras, o patrimônio se encontra na paisagem composta por mar, sol, praia, rio, áreas piscatórias, florestas etc.

Tentei desenvolver, neste artigo, uma reflexão calcada na lógica da descoberta cujo olhar privilegia as práticas sociais de moradores, os principais construtores de uma cidade, além dos projetos urbanísticos. Essas práticas são reveladoras das disputas simbólicas entre cidades onde se destaca uma das suas dimensões, ou seja, a noção moderna de trabalho que separa, contrapondo trabalho ao lazer ou ócio (ou tempo livre), confundindo trabalho e emprego - ou trabalho assalariado - nas fábricas.

Na cidade de São Paulo, as atividades não se restringem, portanto, ao trabalho assalariado; há lazer também. Do mesmo modo, as cidades do Rio de Janeiro e de Salvador não seriam cenários apenas de atividades de entretenimento ou de lazer, pois tais atividades pressupõem também emprego e trabalho de alguém. Ao finalizar este artigo, lembro das observações do escritor Mia Couto (2003, p. 73), ao considerar que uma “... cidade não é um lugar. É a moldura de uma vida. A moldura à procura de retrato. É isso que vejo quando revisito o meu lugar de nascimento."

Recebido para publicação em 02 de maio de 2014 Aceito em 10 de dezembro de 2015
BLASS, Leila. Produzindo o desfile: o trabalho no barracão da escola de samba. São Paulo: Faculdade de Ciências Sociais PUCSP. Margem, n. 8, 1998.

. Dois de fevereiro, dia de Iemanjá: dia de festa no mar. São Paulo: Faculdade de Ciências Sociais PUCSP. Projeto História, n. 28, jun. 2004.

A formação multicultural do trabalhador assalariado brasileiro: o invisível pertinente. In: Chaia, M. e Silva, Ana A. (Orgs). Sociedade, cultura e política. Ensaios críticos. São Paulo: EDUC, 2004.

Nas interfaces do trabalho, emprego e lazer. Caderno CRH. Salvador: EDUFBA, v. 17, n. 41, p. 231-242, maio/ago. 2004

. O ato de trabalhar e suas múltiplas faces. In: Blass, $\overline{\mathrm{L} .}(\mathrm{Org})$, Ato de trabalhar: imagens e representações. São Paulo: AnnaBlume, 2006.

. Desfile na avenida, trabalho na escola de samba: a dupla face do Carnaval. São Paulo: AnnaBlume, 2007.

. Os circuitos da cultura na Virada Cultural em São Paulo. Ponto\&Vírgula, São Paulo: PUC S. Paulo, n. 4, jul. / dez. 2008.

; PAIS, J. M. (Orgs). Tribos urbanas: produção artística e identidades. São Paulo: AnnaBlume, 2004. 1a. edição

CANEVACCI, M. A cidade polifônica: ensaio sobre a antropologia da comunicação urbana. São Paulo: Studio Nobel, 1993.

COUTO, Mia. Beira. Águas do meu princípio, Tabacaria $\mathrm{n}^{\circ}$ 12. Lisboa: Casa Fernando Pessoa, out. 2003.

FERREIRA, Claudino. Os intermediários culturais e cidade. In: Fortuna, C.; Leite, Rogério P. (Orgs). Plural de cidades: novos léxicos urbanos. Coimbra: Almedina/ Centro de Estudos Sociais, 2009.

FORTUNA Carlos; PEIXOTO, Paulo. A recriação e reprodução de representações no processo de transformação das paisagens urbanas de algumas cidades portuguesas. In: Fortuna, C. e Silva, Augusto S. (Orgs). Projecto e circunstância. Culturas urbanas em Portugal. Porto: edições Afrontamento, 2002.

; Sociologia e práticas de lazer. Revista Crítica de Ciências Sociais, n. 43, Coimbra: Centro de Estudos Sociais, outubro 1995.

GONÇALVES, António J.; SILVA, Nuno A. Cidades. Pessoas. Tabacaria. Lisboa, Casa Fernando Pessoa, outono de $2003, n^{\circ} 12$, p. 8.

JEUDI, Henry-Pierre. Espelho das cidades. Rio de Janeiro: Casa da Palavra, 2005.

LEMOS, Carlos. O morar no modernismo paulistano. In: $O$ Caderno de São Paulo - Um empreendimento Rhodia. São Paulo: Rhodia S.A, 1979.

\section{REFERÊNCIAS}

BARREIRA, Irlys. Os guias turísticos em Berlim. São Paulo: Faculdade de Filosofia, Letras e Ciências Humanas da USP. Tempo Social, v. 17, n. 1. p. 299-320, jun. 2005.

. Narrativas de Lisboa. In: Fortuna, C. e Leite,

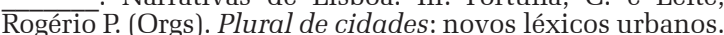
Coimbra: Almedina/ Centro de Estudos Sociais, 2009.

BECKER, H. Falando da sociedade. Ensaios sobre as diferentes maneiras de representar o social. Rio de Janeiro: Jorge Zahar ed., 2009. 


\section{BEYOND ITS NAME: São Paulo, city of work}

\section{Leila Maria da Silva Blass}

This article explores the identity representations concerning the different Brazilian cities, as expression of the dynamics of rivalry between them. In this sense, the article questions the discourse regarding the city of São Paulo, which considers it to be, basically, a city of work, the "locomotive" of Brazil and, therefore, a symbol for the development of the country. One of the main objectives is to show that the notion of work created in Western, European modernity models the ideology regarding the cities, such as, for example, Rio de Janeiro and Salvador. Postcards purchased in September 2002 (at Congonhas Airport, before a flight from São Paulo to Rio de Janeiro; and at Santos Dumont Airport, in Rio, before the return flight) are understood, in the analysis proposed here, as visual metaphors, and some musical compositions are sound metaphors. Thus, they constitute the main source of data for the study.

Keywords: Cities. Social representations. Stigmas. Work. Employment.
POUR ALLER AU-DELA DE SON NOM: São Paulo, la ville du travail

\author{
Leila Maria da Silva Blass
}

Cet article analyse les représentations identitaires de différentes villes brésiliennes en tant qu'expression d'un jeu de rivalités entre elles. En ce sens, on remet en question le discours concernant la ville de Sao Paulo dans lequel elle est essentiellement considérée comme la ville du travail, la "locomotive “ du Brésil et, par conséquent, comme le symbole du développement du pays. L'un des principaux objectifs serait de pouvoir démontrer que la notion de travail inventée dans la modernité européenne occidentale modèle l'idéologie ds villes comme c'est le cas, par exemple, pour Rio et Salvador. Les cartes postales achetées en septembre 2002 respectivement dans les aéroports de Congonhas, au départ de Sao Paulo pour aller à Rio, et dans celui de Santos Dumont pour faire le trajet inverse de Rio à Sao Paulo, sont conçues, dans l'analyse que nous présentons, comme des métaphores visuelles et certaines compositions musicales en seraient des métaphores sonores. Elles sont ainsi leur principale source de données.

Mots-CLÉS: Villes. Représentations sociales. Stigmates. Travail. Emploi.

Leila Maria da Silva Blass - Doutora em Sociologia. Professora titular no departamento de Sociologia da Faculdade de Ciências Sociais e no Programa de Estudos Pós-graduados em Ciências Sociais na Pontifícia Universidade Católica de São Paulo, Brasil. Pesquisadora do CNPq. Líder do Núcleo de Estudos Trabalho, Trabalhadores e Trabalhadoras (NETTT), registrado no Diretório dos Grupos de Pesquisa do Brasil. Recentemente, vem desenvolvendo estudos na área da Sociologia da Vida Cotidiana e seus desafios teórico-metodológicos nos quais se incluem as questões relativas aos diversos modos de envelhecer. Publicações recentes: A dimensão pedagógica da Embaixada do Samba. Ponto-e-Vírgula (PUCSP), v. 10, p. 46-56, 2011; Trabalho no fazer artístico. Ponto-e-Vírgula (PUCSP), v. 6, p. 49-63, 2009; Rompendo fronteiras: a Cidade do Samba no Rio de Janeiro. Revista Brasileira de Ciências Sociais, v. 23, p. 79-92, 2008. 